\title{
Effects of an innovative group program of multisensory stimulation of older adults
}

\author{
Ana Torres ${ }^{\mathrm{a} *}$, Joana Venâncio ${ }^{\mathrm{b}}$ \\ * Corresponding author: Ana Torres, anatorres@ua.pt \\ ${ }^{a}$ Assistant Professor Dr, University of Aveiro, ESEnfCVPOA, Cintesis, Aveiro, Portugal, anatorres@ua.pt \\ ${ }^{b}$ Master Student, University of Aveiro, Aveiro, Portugal, joanafvenancio@ua.pt
}

\begin{abstract}
http://dx.doi.org/10.15405/epsbs.2016.07.02.37

Background: Aging presents a risk for worsening health and quality of life (QoL). Multisensory stimulation programs (MSP) can promote health and QoL of older adults. Art and Mindfulness are innovative strategies. This study has the following purposes: to present an innovative MSP, with art and strategies based in Mindfulness, of 10 sessions to implement in a group of older adults; to present the verified effects of MSP in cognitive functioning, depressive symptomatology and quality of life of Portuguese older adults. Methods: 33 older adults, aged 65 to 94 years old $(\mathrm{M}=82.18, \mathrm{SD}=7.85)$, participated in 2 groups, group with intervention (GI, $\mathrm{n}=16)$ and a waiting group (GC, n=17). A sociodemographic and clinical questionnaire was used, as well as the following evaluation instruments: Mini Mental State Examination; Patient Health Questionnaire-9; WHOQOL-OLD. We also used the MSP developed, with 10 biweekly sessions. Results: We registered a decrease of depressive symptomatology and an increase of the global and some QoL facets (autonomy; activities, social participation and death), as well as, a decrease of the facet of intimacy from pre to post test of the GI; a decrease of the QoL facet sensory functioning from the pre to post test of the GC. Conclusions: The results obtained allow us to conclude that MSP program, with art and strategies based in Mindfulness, is effective on maintain cognitive function, diminish depressive symptomatology and increase QoL of older adults. Taking into account the importance of the results to "give quality to the years" of older adults, future studies with this and similar programs are encouraged.
\end{abstract}

(C) 2016 Published by Future Academy www.FutureAcademy.org.uk

Keywords: Multisensory stimulation; art; Mindfulness; group intervention; older adults.

\section{Introduction}

In recent decades, the aging population is increasing notoriously in the world and in Portugal (INE, 2014). Therefore, world population is expected to be comprised of a progressively bigger proportion of elderly individuals. Human aging is an inevitable process and, as such, implies a process of 
transformation and progressive change in biological, psychological and social structure (Ortiz, Ballesteros, \& Carrasco, 2006). That being said, usually there is an increased dependence of the elderly in their family members, with the latter often taking the role of caregivers. These have to manage functionally cognitive and sensory impairments of aged individuals, as well as often have to deal with behavioral and personality changes (Tooth et al., 2008).

Brain aging is characterized by decreased cognitive processing speed associated with loss of brain neuronal volume, that varies from individual to individual. The WHO (2005) refers that the normal aging process, encloses a decline of some cognitive skills, like learning and memory.

\section{Problem Statement}

The cognitive function begins to deteriorate with advancing age and there are common consequences to various psychological and social aspects, such as the loss of significant people, the loss of employment and entry into the retirement, which can lead to a perception of uselessness, isolation and, therefore, loneliness (Torres Pires, 2008). Therefore, the author says that there is risk that old age can lead to depressive, aggressive and frustrated states, and dementia symptoms. Thus, depression is very frequent in the elderly, which significantly compromises the QoL (Greenwald, Kramer-Ginsberg, \& Krishman, 1996 cit. in Gonçalves, 2012).

Baltes and Smith (1999, cit. in Fonseca, 2006) argue that there is a very close relationship between the sensory functioning and cognitive functions, stated that diminished sensory functioning causes an impoverishment in cognitive functioning. In recent years, sensory and cognitive stimulation has had a significant importance in the rehabilitation of subjects. Zimerman (2000) argues that stimulation is a way to achieve the reduction of the adverse effects of aging, such as decreased memory, processing speed, executive function, among others, providing the elderly with an increased QoL.

Sensory stimulation allows to promote healthy aging and to control some characteristics of aging (Gordon-Nesbit, 2015; Martins, 2011; Overshott \& Burns, 2006 cit in. Torres Pires, 2008). Multisensory therapy stimulates the primary senses, such as sight, hearing, taste, touch and smell, with light effects, meditative, tactile surfaces and aromatherapy (Torres Pires, 2008). Thus, nonpharmacological therapies have been shown to be effective in terms of behavioral symptoms such as agitation, apathy and drowsiness, and also had effects in improving depressive symptoms, self-esteem and well-being of patients (Overshott \& Burns, 2006 cit. in Torres Pires, 2008). The multisensory environment is an environment in which therapy is combined with recreation, relaxation and pleasant sensory experiences (Martins, 2011), such as music and art, to the benefit of the elderly.

The artistic content has stimulating effects and there are studies that give support to this idea. Art offers strategies to channel the frustration, anger, disappointment and fear through imagination (Gordon-Nesbit, 2015). Thus, several studies have shown that frequent presence in cultural events such as concerts, movies, art exhibitions in museums, is associated with better survival rates (Bygren, Konlaan, \& Johansson, 1996), lower risk of dementia (Wilson et al., 2002) and better self-health perception (Wilkinson, Waters, Bygren, \& Tarlov, 2007). Windle et al (2014) argue that nonpharmacological approaches such as activities based on arts (e.g. dance, music, creative writing, visual art and singing), can help people with dementia to live in a better health condition and combat the 
http://dx.doi.org/10.15405/epsbs.2016.07.02.37

eISSN: 2357-1330 / Corresponding Author: Ana Torres

Selection and peer-review under responsibility of the Organizing Committee of the conference

negative aspects of the disease. The same authors argue the potential of these programs to improve the well-being, QoL, cognitive function, creative thinking and communication, facilitating reminiscence and increased self-esteem. The quality of the reading habits and poetry improves QoL in the dependent elderly, reduces anxiety and stress (Reiter, 1994 cit. in Cohen et al., 2006; Stern, 2009).

Music presents significant stimulation capacity of attention and memory (Sarkamo et al., 2008). The authors emphasize a higher capacity of the musical component, or a combination of speech and music, in recovering cognitive functions. The study by Chan et al (2012) argues that music is effectively used as an intervention to relieve depression for older adults. The study by Murrock e Higgins (2009) indicated that the music evokes a psychological response that alters mood and leads to better health outcomes.

According to Rios et al (2013), providing entertainment and stimulation activities for the elderly reduces the chance of memory loss, especially for institutionalized individuals who are separated from their families. That being said, drawing activities allow you to recall some past experiences, but also represent the feelings and desires of those present and dissatisfaction with life. According to the authors, drawing or painting activities also gives seniors a chance to use and remember colors and shapes.

Mindfulness is a concept originating in the Eastern meditative practices and refers to a specific form of paying attention (Lima, Oliveira, \& Godinho, 2011). The practice of this strategy requires the presence of three key elements, i.e., focused attention on the present moment, intentionality and absence of judgment (Kabat-Zinn, 1990). Lima et al (2011) studied the promotion of well-being in the elderly, with recourse to training in mindfulness and highlight the benefits of mindfulness meditation for older adults, in particular, cognitive, emotional, physiological and behavioral level.

\section{Research Questions}

In this research we will focus on analyzing the impact the MSP, with art and strategies based in Mindfulness, into the cognitive functioning, depressive symptomatology and QoL in older adults. Our main research question is: What is the effect of 10 group sessions of MSP, with art and strategies based in Mindfulness, into the cognitive functioning, depressive symptomatology and QoL of older adults?

\section{Purpose of the Study}

This study has the following purposes: to present an innovative MSP, with art and strategies based in Mindfulness, of 10 sessions to implement in a group of older adults; to present the verified effects of MSP into cognitive functioning, depressive symptomatology and QoL of Portuguese older adults.

\section{Research Methods}

\subsection{Sample}

The sample of participants consisted of 33 older adults, aged from 65 to 94 years old $(\mathrm{M}=82.18$, $\mathrm{SD}=7.85)$, participated in 2 groups, group with intervention (GI, $\mathrm{n}=16$ ) and a waiting group (GC, $\mathrm{n}=17)$. 


\subsection{Assessment tools}

To collect data we used the sociodemographic and clinical questionnaire, for characterization of the subject by sex, age, marital status, capability of reading and writing, presence/absence of disease and dementia problems, medication and questions about preemptive and feature frequency at arts (reading, poetry, painting and music). The following evaluation instruments were used:

- MMSE (Mini Mental State Examination of Folstein, Folstein, \& Mchugh, 1975; Guerreiro et al., 1994) to evaluate the change in cognitive state of geriatric patients. It consists of eleven items divided into two sections. Regarding scoring, one point is awarded for each correct answer, for a total score of 30 points. It presents a Cronbach's alpha of .46 (Morgado, Rocha, Maruta, Guerreiro, \& Martins, 2009) and high test-retest reliability and good agreement interrater (between general practitioners and between neuropsychologists), evaluated by the Pearson coefficient, .89 and .83, respectively (Folstein et al., 1975). In this study, the internal consistency value $(\alpha=.68)$ and as the construct of test-retest validity submitted an acceptable value $(r s=.80, \mathrm{p}<.001)$.

- PHQ-9 (Patient Health Questionnaire-9, Kroenke, Spitzer, \& Williams, 2001; Torres, Pereira, Monteiro, \& Albuquerque, 2013) consisting of nine questions assessing the presence of symptoms for each of the episode of major depressive disorder described in the Diagnostic and Statistical Manual of Mental Disorders (DSM-V) (APA, 2014). This makes it a dual purpose instrument that, with the same nine items, can establish provisional diagnosis of disturbance of depression, but also the degree of severity of depressive symptoms (Kroenke \& Spitzer, 2002). The frequency of each symptom in the last two weeks is evaluated on a Likert scale 0-3 (Santos et al., 2013). The questionnaire also includes a tenth question that evaluates the interference of these symptoms in the performance of daily activities. The results of the PHQ-9 are comprised between 0 and 27 points, with cohort points of 5, 10, 15 and 20, which represent mild depression threshold, mean, moderate and severe, respectively (Kroenke et al. 2001). This instrument has good psychometric characteristics, good internal consistency $(\alpha=.82)$ and ICC (.87) (Torres et al., 2013). In this study, the PHQ-9 showed high internal consistency $(\alpha=.64)$ although lower than the original study, but has a reasonable validity test-retest $\left(r_{S}=.69, \mathrm{p}<.001\right)$, indicating this instrument is sensitive to the differences between the two time points.

- WHOQOL-OLD (Power, Quinn, \& Schmidt, 2005; Vilar \& Simões, 2009) to evaluate the QoL in older adults (Vilar, Sousa, \& Simões, 2015). In original version, it consists of six facets: Sensory Functioning (evaluates the sensory functioning and impact of the loss of sensory abilities participation in activities and interaction), Autonomy (ability to live independently and make decisions), Past, Present and Future Activities (assesses satisfaction with achieved goals in life and projects to accomplish), Social Participation (assesses participation in everyday activities, particularly in the community), Death and Dying (rating concerns and fears about death and dying), and Intimacy (assesses the ability to have personal and intimate relationships), with a Likert scale of five points (1-5). In the context of adaptation studies, validation and standardization for the Portuguese people, the instrument integrates 4 more items in a new facet, Family/Family Life (assesses satisfaction with the time spent in family support 
and family relationships and the meaning of the old value in the family) (Vilar et al., 2015). The WHOQOL-OLD has items listed inversely (items 1, 2, 3, 7, 8, 9 and 10). Internal consistency (.91) and temporal stability (.80) were excellent in the Portuguese version. The internal consistency assessed by Cronbach's alpha is acceptable, both in the group of seven facets $(\alpha=.85)$, as in every facet, i.e., ranging from $\alpha=.60$ (the facet past, present and future activities) to $\alpha=.96$ (the facet of intimacy). For the test-retest validity construct is acceptable, ranging from $r_{S}=.71$ (in sensory functioning facets and past, present and future activities) to $r_{S}=.92$ (the facet autonomy), all with $\mathrm{p}<.001$.

- We used the Multisensory Stimulation Program (MSP) developed. The MSP was based on the implementation of various activities aimed at the stimulation of different senses, including visual, auditory, olfactory and tactile as well as stimulation of various cognitive functions such as thinking, attention, concentration, imagination and association of ideas. The main objectives of the implemented MSP are consistent with the ones described above, i.e., improve QoL and well-being of the elderly, stimulate cognitive functions, provide psychological support to develop the relationship between education and health, promote the socialization of the elderly to prevent isolation situations (Camara et al., 2009) but also the depressive symptoms and stimulate the sensory functions. The activities conducted during the MSP are similar to the activities applied in other studies with similar goals (Amodeo, Netto, \& Fonseca, 2010; Apóstolo, Cardoso, Marta, \& Amaral, 2011; Liesk, Hartogh, \& Kalbe, 2015). The literature suggests that musical activity has significantly positive effects on the level of depression (Chan et al., 2012), subjective well-being (Creech, Hallam, Varvarigou, McQueen \& Gaunt cit. in Liesk et al., 2015) and QoL (Lee, Chan, \& Mok, 2010) in the elderly. According to the Arts Council England (2014), several studies show that artistic and cultural activities can have a positive impact on the symptoms related to health conditions linked to cognition, physical stability, self-esteem and the ability of people to cope with it through changes in behavior and increased social contacts. The involvement of high quality artistic activities in non-clinical settings (e.g., galleries and museums, theaters, cinemas and concerts) may potentiate the effect on physical and mental health. The program lasts for five weeks, with 10 biweekly sessions, in group, lasting 45 to 60 minutes, similar to other studies with the same goal (Amodeo et al., 2010; Rodrigues, 2006). Each session begins with a brief summary of the sensory stimulation objectives to be achieved with certain activities for each session. At the end of each session, participants are invited to share what they felt and thought about each session by choosing keywords, registered in cardboard.

\subsection{Procedure}

Participants were from three institutions: two nursing homes and a day center. The inclusion criteria were the following: aged 65 or older, have higher values on the MMSE to the cutoff points found in the original study (dementia absence supposed). As exclusion criteria, in addition to the values below the cutoff point and the age of 65 , we also defined the existence of language deficits, auditory or visual, that can hinder the participation and performance activities, as well as, the presence of psychological 
disorders or psychiatric or personality characteristics that hinder participation in the group, in addition to being bedridden elderly.

The distribution of participants was held by motivation and interest in participation in the MSP.

This study includes an assessment phase and an intervention stage. Thus, the evaluation phase is constituted by the pre and post-test sessions. In these sessions we applied the assessment tools previously described (MMSE, PHQ-9 and WHOQOL-OLD). These instruments were applied before starting the program (pre-test) and after (post-test) to measure the differences in cognitive functioning, depressive symptoms and QoL. In fact, at every stage of research ethical guidelines were provided, including that the treatment of participants during the study was conducted in compliance with the ethical standards of the American Psychological Association (APA, 2010). We also clarified some doubts that have arisen, particularly in terms of difficulty of the activities, which was the main concern of the participants. In the evaluation at the post-test session we also placed two additional questions to the participants, which were as follows: "Since the first time we were together, did happen some event that had a significant influence on you?" as well as "Was there any change in medication since the first time we were together?". The making of these additional questions intended to control the influence of external variables (significant life events and medication) in the experimental results.

The intervention phase consists of the implementation of the program. It also took into account the qualitative data collection at the end of each session and the end of the post-test. In preparing the MSP we resorted to literature, to proceed to the selection of tasks to be applied to participants. After this selection, we made use of a participating pilot who selected the songs, pictures and poems from a variety of options. This pilot participant, volunteer, had matching characteristics with the target population. It was also with this participating pilot that we tested the selected assessment procedures and intervention sessions. It was in this way that we selected all procedures that we used on the participants in the study.

\subsection{Data analysis}

In this research, taking into account the nature of the problem, we chose a research paradigm with a quantitative approach. The treatment of quantitative data for statistical analysis of internal consistency we used Cronbach's alpha having as a criterion the value of .60, which, according to the indications of Nunnally (1978), indicates an applicable internal consistency to value research purposes (including individual assessment for educational or clinical intervention). Statistical analysis was performed using the SPSS 21. The level of statistical significance was set at $\mathrm{p}<.05$. According to Cohen (1992), the values of $.10, .30$ and .50 are considered small effect sizes, medium and high, respectively. Analysis of the kurtosis and skewness and the Levene test lead to the option for non-parametric tests.

\section{Findings}

\subsection{Socio-demographic data}

We found no significant differences in the age distribution by experimental design $[\mathrm{U}=128.50$, $\mathrm{p}>$.05] (Table 1). The sample is divided into two groups, the intervention group (GI, $\mathrm{n}=16)$ and control 
group (GC, $\mathrm{n}=17)$. The GI consists of five elderly males and 11 females, aged between 65 and 94 years $(\mathrm{M}=81.56, \mathrm{SD}=8.63)$. While the $\mathrm{GC}$ consists of 6 elderly males and 11 females, with minimum and maximum age of 65 and 94 , respectively $(M=82.76, \mathrm{SD}=7.25)$. The groups did not differ with respect to clinical variables (disease and prescribed medication). For the variables related to art, we find that there are differences between the two groups in the liking for poetry, in which $75.8 \%$ like poetry $(\chi 2=5.48, p<.05)$, the frequency use of poetry, in which $30.3 \%$ do not read poetry $(U=82.50, p<.05)$ and the frequency use of painting, in which $48.5 \%$ do so once a week $(U=110.00, p<.05)$. Regarding the study variables (cognitive function, depressive symptoms and QoL), we find that comparing our sample with the validation results of the Portuguese population, that there is greater cognitive impairment, reduced depressive symptoms, better overall quality of life and higher results in all facets except intimacy in our sample. In this study there was a drop-out (female participant), due to the onset of dementia that presented, noting spatial disorientation and temporal going to present one of the exclusion criteria.

Table 1. Characterization of the sample for experimental design, sex, marital status and educational qualifications

\begin{tabular}{|c|c|c|c|c|c|}
\hline & & Total $(n=33)$ & GI $(n=16)$ & $\mathrm{GC}(\mathrm{n}=17)$ & GI $v_{s} \mathrm{GC}$ \\
\hline & & N (\%) & N (\%) & N (\%) & $X^{2}, \mathrm{p}$ \\
\hline \multicolumn{2}{|c|}{ Experimental design } & $33(100 \%)$ & $16(48.5 \%)$ & $17(51.5 \%)$ & \\
\hline \multirow[t]{2}{*}{ Sex } & Male & $11(33.3 \%)$ & $5(31.3 \%)$ & $6(35.3 \%)$ & .06 \\
\hline & Female & $22(66.7 \%)$ & $11(68.8 \%)$ & $11(64.7 \%)$ & \\
\hline \multirow[t]{5}{*}{ Marital Status } & Not married & $4(12.1 \%)$ & $1(6.3 \%)$ & $3(17.6 \%)$ & 2.35 \\
\hline & Married & $3(9.1 \%)$ & $1(6.3 \%)$ & $2(11.8 \%)$ & \\
\hline & Facto f Union & $0(0 \%)$ & $0(0 \%)$ & $0(0 \%)$ & \\
\hline & Divorced & $1(3 \%)$ & $1(6.3 \%)$ & $0(0 \%)$ & \\
\hline & Widower & $25(75.8 \%)$ & $13(81.3 \%)$ & $12(70.6 \%)$ & \\
\hline \multirow[t]{4}{*}{ Qualifications } & Illiterate & $9(27.3 \%)$ & $5(31.3 \%)$ & $4(23.5 \%)$ & 3.13 \\
\hline & Primary school & $21(63.6 \%)$ & $10(62.5 \%)$ & $11(64.7 \%)$ & \\
\hline & High school & $2(6.1 \%)$ & $0(0 \%)$ & $2(11.8 \%)$ & \\
\hline & Higher education & $1(3.0 \%)$ & $1(6.3 \%)$ & $0(0 \%)$ & \\
\hline
\end{tabular}

\subsection{Quantitative results}

We used the Mann-Whitney test to test the equivalence of the groups in the first evaluation. The groups are equivalent, even though the participants are more autonomous GI (Mdn=17.50), differing $\mathrm{GC}(\mathrm{Mdn}=15.00)$ in pre-test, $\mathrm{U}=66.50, z=-2.52, \mathrm{p}<.05 \mathrm{r}=-.44$, with an average size effect.

The Wilcoxon test was used to compare the two moments of evaluation of each group. Thus, we can see that the GC only found statistically significant differences in sensory functioning (evaluate by WHOQOL-OLD) between pre and post-test, with an medium effect size. However, in the GI there are statistically significant differences in different variables evaluated, namely: decrease in the levels of depression between pre and post-test, with an average effect size; the overall quality of life shows an increase between the first time and the second time with a medium effect size; autonomy shows a significant increase between the beginning and the end, with a medium effect size; the facet of past 
present and future activities shows a significant increase between pre and post-test, with a medium effect; social participation show a significant increase between the first and second assessment, with a high effect; the facet death observed an increase between pre and post-test, with a medium effect; finally, intimacy facet shows a decrease between the pre and post-test, with an medium effect.

To check the results of the intervention also we applied the Mann-Whitney test to compare the groups in the second assessment, and found differences between medians of the two groups related to quality general life and the various aspects of QoL (sensory functioning, autonomy, past, present and future activities, and social participation). It was noted that the participants of the GI have higher levels of quality of life in general $(\mathrm{Mdn}=112.50)$ compared to the GC (Mdn=99.00), in a significant way, $\mathrm{U}=62.00, z=-2.67, \mathrm{p}<.01, \mathrm{r}=-.47$, with a medium effect size. It was found that the GI has a better perception of sensory function ( $\mathrm{Mdn}=18.00)$ after stimulation sessions, opposing to $\mathrm{GC}(\mathrm{Mdn}=14.00)$, $\mathrm{U}=68.00, z=-2.47, \mathrm{p}<.05, \mathrm{r}=-.43$, with a mean effect size. It was found that the GI has a better perception of autonomy ( $\mathrm{Mdn}=18.50)$ after the MSP, opposing to GC $(\mathrm{Mdn}=14.00), \mathrm{U}=50.50, z=-3.11$, $\mathrm{p}<.01, \mathrm{r}=-.54$, with a high effect. Regarding the aspect of past, present and future activities in the program end, the GI has greater perception of this facet $(\mathrm{Mdn}=17.00)$ compared to the GC $(\mathrm{Mdn}=13.00)$, verifying significant differences, $\mathrm{U}=45.00, z=-3.30, \mathrm{p}<.01, \mathrm{r}=-.57$, with a high effect. And yet, GI participants have higher levels of social participation ( $\mathrm{Mdn}=18.00)$ after the program compared to the GC $(\mathrm{Mdn}=15.00)$, noting significant differences, $\mathrm{U}=65.00, z=-2.58, \mathrm{p}<.05, \mathrm{r}=-$. 45 , with a medium effect size.

\section{Conclusions}

Population aging is a reality in Portugal and in the world, becoming, increasingly, a concern and the subject of some research in the field of health and psychology. And since to care for the elderly is to value our history and future, we must allow and promote a greater well-being and QoL to this age group. Thus, this study is of greatest importance because of this need to "give quality to the years" (Torres Pires, 2008) and there is still much to do in this area.

Thus, with the review of literature conducted it was found that most of the population is aging and, with this feature, present with high levels of depression, deterioration of cognitive functioning and lower levels of QoL. That said, it is crucial to act in this age group with strategies that provide better well-being, self-esteem, greater life satisfaction, and, therefore, better QoL.

The multisensory stimulation evidenced to have effects on maintenance of cognitive performance, reduction of depressive symptomatology and increased perception of quality of life for the elderly. Thus, we emphasize the benefits of the program, referring activities that are easy to implement and low cost. We also believe that these results were achieved due to the implementation of strategies based on mindfulness, in which people are oriented to focus on the moment, not worrying about the past and the future.

In future research, we argue that the assessment tools and intervention programs studied in this research should continue to be studied in the future in order to test the generalization of the results. Intervention programs should ideally be studied under completely randomized and double-blind studies. We emphasize also the importance of identifying external factors to the intervention program 
that can influence the decrease or increase cognitive functioning, depressive symptoms and QoL. Moreover, to obtain greater and more representative sample of the elderly population would also be desirable. And yet, implement MSP in follow-up sessions, to maintain, strengthen and clarify these results.

\section{References}

Amodeo, M. T., Netto, T. M., \& Fonseca, R. P. (2010). Desenvolvimento de programas de estimulação cognitiva para adultos idosos : modalidades da Literatura e da Neuropsicologia. Letras de Hoje, 45(3), 54-64. Retrieved from http://revistaseletronicas.pucrs.br/ojs/index.php/fale/article/view/8121/5810

APA, A. P. A. (2010). Publication Manual of the American Psychological Association (6 ${ }^{\mathrm{a}}$ ed.). Washington DC: American Psychological Association.

APA, A. P. A. (2014). Manual de Diagnóstico e Estatística das Perturbações Mentais (5ª ed.). Lisboa: American Psychiatric Association.

Apóstolo, J., Cardoso, D., Marta, L., \& Amaral, T. (2011). Efeito da estimulação cognitiva em idosos. Revista de Enfermagem Referência, 3(5), 193-201. Retrieved from http://www.scielo.mec.pt/pdf/ref/vserIIIn5/serIIIn5a20.pdf

Arts Council England. (2014, March). The Value of Arts and Culture to People and Society: an evidence review, pp. 1-53. Manchester. Retrieved from http://www.artscouncil.org.uk/media/uploads/pdf/The-value-of-artsand-culture-to-people-and-society-An-evidence-review-Mar-2014.pdf

Bygren, L. O., Konlaan, B. B., \& Johansson, S. E. (1996). Attendance at cultural events, reading books or periodicals, and making music or singing in a choir as determinants for survival: Swedish interview survey of living conditions. British Medical Journal, 313(1), 1577-1580. Retrieved from http://www.ncbi.nlm.nih.gov/pmc/articles/PMC2359094/pdf/bmj00573-0013.pdf

Camara, V. D., Gomes, S. S., Ramos, F., Moura, S., Duarte, R., Costa, S. A., ... Fonseca, A. A. (2009). Reabilitação Cognitiva das Demências. Revista Brasileira de Neurologia, 45(1), 25-33.

Chan, M. F., Wong, Z. Y., Onishi, H., \& Thayala, N. V. (2012). Effects of music on depression in older people: a randomised controlled trial. Journal of Clinical Nursing, 21(5-6), 776-83. doi:10.1111/j.13652702.2011.03954.x

Cohen, G. D., Perlstein, S., Chapline, J., Kelly, J., Firth, K. M., \& Simmens, S. (2006). The impact of professionally conducted cultural programs on the physical health, mental health, and social functioning of older adults. The Gerontologist, 46(6), 726-734. doi:10.1093/geront/46.6.726

Cohen, J. (1992). A power primer. Psychological Bulletin, 112(1), 155-159.

Folstein, M., Folstein, S., \& Mchugh, P. (1975). Mini-mental state: A practical method for grading the cognitive state of patients for the clinician. Journal of Psychiatric Research, 12(3), 189-198. Retrieved from http://www.journalofpsychiatricresearch.com/article/0022-3956\%2875\%2990026-6/pdf

Fonseca, A. (2006). O envelhecimento: Uma abordagem psicológica ( $2^{\mathrm{a}}$ Edição.). Lisboa: Universidade Católica Editora.

Gonçalves, C. (2012). Programa de estimulação cognitiva em idosos institucionalizados. O Portal dos Psicólogos. Retrieved November 7, 2015, from http://www.psicologia.pt/artigos/textos/A0623.pdf

Gordon-Nesbit, R. (2015). Longitudinal Arts Engagement and Health. Manchester: Manchester Metropolitan University. Retrieved from http://longitudinalhealthbenefits.wordpress.com

Guerreiro, M., Silva, A., Botelho, M., Leitão, O., Castro Caldas, A., \& Garcia, C. (1994). Adaptação à População Portuguesa na tradução do "Mini Mental State Examination (MMSE). Revista Portuguesa de Neurologia, $1(9)$.

INE, I. N. de E. (2014). Projeções de População Residente. Retrieved October 13, 2015, from $\mathrm{https} / / /$ www.ine.pt/xportal/xmain?xpid=INE\&xpgid=ine_destaques\&DESTAQUESdest_boui=208819970\& DESTAQUESmodo $=2$

Kabat-Zinn, J. (1990). Full Catastrophe Living: Using the wisdom of your body and mind to face stress, pain, and illness. New York: Delta.

Kroenke, K., \& Spitzer, R. L. (2002). The PHQ-9 : A New Depression Measure. Psychiatric Annals, 32(9), 509515. doi:170553651

Kroenke, K., Spitzer, R. L., \& Williams, J. B. W. (2001). The PHQ-9: Validity of a brief depression severity measure. Journal of General Internal Medicine, 16(9), 606-613. doi:10.1046/j.15251497.2001.016009606.x

Lee, Y. Y., Chan, M. F., \& Mok, E. (2010). Effectiveness of music intervention on the quality of life of older 
people. Journal of Advanced Nursing, 66(12), 2677-87. doi:10.1111/j.1365-2648.2010.05445.x

Liesk, J., Hartogh, T., \& Kalbe, E. (2015). Kognitive Stimulation und Musikintervention bei stationär versorgten Menschen mit Demenz. Zeitschrift Für Gerontologie Und Geriatrie, 48(3), 275-281. doi:10.1007/s00391014-0661-6

Lima, M. P., Oliveira, A. L., \& Godinho, P. (2011). Promover o bem-estar de idosos institucionalizados: Um estudo exploratório com treino em mindfulness. Revista Portuguesa de Pedagogia, 45(1), p. 165-183. Retrieved from http://98.130.112.242/index.php/rppedagogia/article/view/1299

Martins, A. (2011). Snoezelen com Idosos: Estimulação sensorial para melhor qualidade de vida. Retrieved from $\mathrm{http}: / / w w w . f o r b r a i n . p t / u p l o a d s / d o c u m e n t o s / 10$ Snoezelen com Idosos.pdf

Morgado, J., Rocha, C. S., Maruta, C., Guerreiro, M., \& Martins, I. P. (2009). Novos Valores Normativos do MiniMental State Examination. Sinapse, 9(2), 10-16. Retrieved from https://www.researchgate.net/publication/256295628_Novos_valores_Normativos_do_minimental state examination

Murrock, C. J., \& Higgins, P. A. (2009). The theory of music, mood and movement to improve health outcomes Journal of Advanced Nursing, 65(10), 2249-57. Retrieved from http://www.pubmedcentral.nih.gov/articlerender.fcgi? $\operatorname{artid}=3573365 \&$ tool=pmcentrez\&rendertype $=$ abstract

Nunnally, J. C. (1978). Psychometric theory ( $2^{\mathrm{a}}$ ed.). Nova Iorque: McGraw-Hill.

Organização Mundial de Saúde. (2005). Envelhecimento Ativo uma Política de Sáude. Organização PanAmericana da Saúde. Retrieved October 15, 2015, from http://www.prosaude.org/publicacoes/diversos/envelhecimento_ativo.pdf

Ortiz, L. A., Ballesteros, J. C., \& Carrasco, M. M. (2006). Psiquiatría Geriátrica (2ª ed.). Barcelona: Elsevier.

Power, M., Quinn, K., \& Schmidt, S. (2005). Development of the WHOQOL-Old Module. Quality of Life Research, 14(10), 2197-2214. doi:10.1007/s11136-005-7380-9

Rios, T. M. da S., Menezes, T. M. de O. M., Cunha, D. do V., Pereira, L. S. de S., \& Araújo, R. C. (2013). Lazer no envelhecimento: Relato de experiência. Paraninfo Digital, 7(19). Retrieved from http://www.indexf.com/para/n19/pdf/185d.pdf

Rodrigues, M. (2006). Efeitos de uma intervenção psico-educativa nas competências cognitivas e satisfação de vida em idosos. Cadernos de Estudo: Educação Social. Tese de Mestrado. Universidade Fernando Pessoa.

Santos, I., Tavares, B. F., Munhoz, T., Almeida, L. S., Silva, N. T., Tams, B., ... Matijasevich, A. (2013). Sensibilidade e especificidade do Patient Health Questionnaire-9 (PHQ-9) entre adultos da população geral. Cadernos de Saúde Pública, 9(8), 1533-1543. doi:10.1590/0102-311X00144612

Sarkamo, T., Tervaniemi, M., Laitinen, S., Forsblom, A., Soinila, S., Mikkonen, M., ... Hietanen, M. (2008). Music listening enhances cognitive recovery and mood after middle cerebral artery stroke. Brain, 131(3), 866-876. doi:10.1093/brain/awn013

Tooth, L., Russel, A., Lucke, J., Byrne, G., Lee, C., Wilson, A., \& Dobson, A. (2008). Impact of cognitive and physical impairment on carer burden and quality of life. Quality Life Research, 17(1), 267-273.

Torres Pires, A. C. S. (2008). Efeitos dos videojogos nas funções cognitivas da pessoa idosa. Tese de Mestrado. Faculdade de Medicina da Universidade do Porto. Retrieved from http://hdl.handle.net/10216/22139

Torres, A. C. S., Pereira, A., Monteiro, S., \& Albuquerque, E. (2013). Preliminary validation study of a portuguese version of the patient health questionnaire (PHQ-9). European Psychiatry, 28(1), 1. doi:10.1016/S09249338(13)76982-7

Vilar, M. M., \& Simões, M. (2009). WHOQOL-OLD: Manual de Administração e Cotação[European Portuguese WHOQOL-OLD module: Manual for administration and scoring]. Coimbra: Serviço de Avaliação Psicológica da Faculdade de Psicologia e de Ciências da Educação.

Vilar, M., Sousa, L. B., \& Simões, M. R. (2015). World Health Organization Quality of Life-OLD Module (WHOQOL-OLD). In M. R. Simões, I. Santana, \& Grupo de Estudos de Envelhecimento Cerebral e Demência (GEECD) (Coords.) (Eds.), Escalas e Testes na demência ( $3^{\text {a }}$ ed., pp. 194-199). Lisboa: Novartis.

Wilkinson, A. V., Waters, A. J., Bygren, L. O., \& Tarlov, A. R. (2007). Are variations in population health associated with attending cultural activities in the United States? BMC Public Health, 7, 226.

Wilson, R. S., Leon, C. F. M., Barnes, L. L., Schneider, J. A., Bienias, J., Evans, D. A., \& Bennett, D. A. (2002). Participation in Cognitively Stimulating Activities and Risk of Incident Alzheimer Disease. JAMA, 287(6), 742. doi:10.1001/jama.287.6.742

Windle, G., Gregory, S., Newman, A., Goulding, A., O’Brien, D., \& Parkinson, C. (2014). Understanding the impact of visual arts interventions for people living with dementia: a realist review protocol. Systematic Reviews, 3(1), 91. doi:10.1186/2046-4053-3-91

Zimerman, G. I. (2000). Velhice: aspectos biopsicossociais. Porto Alegre: Artes Médicas. 